\title{
INHIBICION DE FUSARIUM GRAMINEARUM POR UNA CEPA DE STREPTOMYCES SP. $\left({ }^{*}\right)$
}

\author{
Alfredo L.Borghi, Cecilia L.Fulgueira y \\ Blanca J.C. de Bracalenti. \\ Departamento de Microbiología. \\ Facultad de Ciencias Bioquímicas y Farmacéuticas. \\ Universidad Nacional de Rosario. Suipacha 531. \\ Rosario (2000). Santa Fe. República Argentina.
}

Palabras clave: Fusarium graminearum. Streptomyces sp. inhibición.

Key words: Fusarium graminearum, Streptomyces sp. inhibition.

\section{RESUMEN}

Se determina el efecto de una cepa de Streptomyces sp. aislada del suelo, sobre la germinación y el crecimiento de Fusarium graminearum NRRL 2830 productor de zearalenona. La germinación se estudió en agar extracto de malta determinándose que: a) En ausencia de Streptomyces sp. en 5,30 horas se obtuvo el $100 \%$ de germinación de los macroconidios, b) Una inhibición completa cuando se inoculan junto a Streptomyces sp., y c) Una inhibición parcial cuando se inoculan junto al filtrado de Streptomyces sp.

El crecimiento, estudiado en el mismo medio de cultivo, también demostró que únicamente la presencia de este Actinomycete fue capaz de inhibir el desarrollo.

\section{INTRODUCCION}

Las especies de Fusarium pueden ser regularmente patógenas de Plantas, a saprófitas sobre materiales vegetales, causantes de la biodegradación de productos industriales y productoras de

(") Trabajo subsidiado por SEC y T.

\section{SUMMARY}

[Fusarium Graminearum inhibition by a strain of Streptomyces $s p$.]

The inhibitory effect of a strain of Streptomyces sp. isolated from soil was determined over the germination and the growth of Fusarium graminearum NRRL 2830, producer of zearalenone.

The germination of conidia was studied in malt extract agar concluding that: a) The germination of macroconidia was produced in a percentage of $100 \%$ during a period of 5,30 hours, in absence of Streptomyces sp., b) When both macroconidia and Streptomyces sp. were inoculated, a complete inhibition was observed, and c) $A$ partial inhibition was observed when macroconidia was inoculated with a filtrate of Streptomyces $s p$.

The growth studied in the same media, showed that the presence of the Actinomycete was necessary for the inhibition of fungal development.

micotoxinas. Dentro de los fitopatogenos, hay especies que causan serios deterioros: pudrición de raíces, muerte de semillas y "gangrenaulcerosa" de los tejidos maduros.

Debido a su estrecha asociación con las plantas y a sus relativamente altos requerimientos de actividad de agua para crecer, los Fusarium usualmente se establecen en los granos antes de la cosecha y pueden causar serios problemas en 
cereales almacenados después de un verano húmedo. Los Fusarium producen un gran número de metabolitos sesquiterpenos llamados trichothecenos, como así también Zearalenona, moniliformina, butenolide y las fusarinas (1). El interés en ellos radica en su amplia distribucion mundial como en la identificación de un número creciente de micotoxinas presentes en forma natural y que son consideradas como productoras de patologías humanas y animales. Estos Fusarium toxicogénicos han sido implicados en enfermedades humanas tales como "aleukia tóxica alimentaria", cáncer esofágico y en enfermedades animales tales como síndrome hemorrágico, estrogénico, hemético, etc. Estudios recientes acerca de que los trichothecenos producidos por especies de Fusarium son componentes de la llamada "lluvia amarilla", han incrementado el interés en estos compuestos altamente tóxicos (2).

En los granos en desarrollo y durante el almacenamiento post cosecha, los hongos son expuestos a interacciones complejas con la especie hospedera y su condición fisiológica y etapa de crecimiento, depende de varios factores, como la presencia de otros microorganismos, de los biocidas aplicados en distintas etapas del desarrollo de la semilla 0 de los preservativos empleados durante su almacenamiento (3).

Se ha demostrado la inhibición del crecimiento de patógenos fúngicos vegetales por Actinomycetes (4). Muchas de las inhibiciones demostradas son debidas a una respuesta del patógeno a las sustancias antimicrobianas producidas por el Actinomycete (5).

En control biológico de agentes que causan enfermedades en vegetales puede ser efectuado tratando las lesiones con otros microorganismos o por inoculación artificial en el suelo de estos, los que pueden ser estimulados para su multiplicación y subsecuente reemplazo del patógeno establecido $(6,7)$.

El propósito de este trabajo fue determinar el poder inhibitorio de una cepa de Streptomyces sp. sobre la germinación y el crecimiento de Fusarium graminearum Schwabe (NRRL 2830), productor de Zearalenona. El Streptomyces empleado, fue seleccionado entre los que produjeron mayor inhibición del hongo.

\section{MATERIAL Y METODOS}

\section{Preparación del inóculo de F.graminearum:}

La cepa fue suministrada por el National Regional Research Laboratory de U.S.A. F. graminearum y fue sembrado en Agar Papa Sacarosa e incubado a $28^{\circ} \mathrm{C}$., 5-6 dias hasta visualizar la conidiogénesis. En ese momento las placas fueron lavadas con una suspensión diluída de Tween 80 que luego fue filtrada a través de seis capas de gasa estéril, procediéndose posteriormente al recuento de la suspensión de conidios resultantes en cámara de Neubauer. Se prepararon suspensiones de aproximadamente $10^{\circ}$ conidios $/ \mathrm{ml}$.

II Aislamiento de una cepa de Streptomyces con propiedades inhibitorias:

La cepa de Streptomyces empleada, se aisló del suelo, entre los que produjeron mayor inhibición del desarrollo del F. graminearum al sembrarse en placas de Agar Extracto de. Malta una suspension de tierra de un campo de cultivo de cereales (próximo a la ciudad de Rosario) y el hongo en estudio.

La cepa de Streptomyces sp. seleccionada fue sembrada en un medio especial para su mantenimiento, consistente en: glucosa $1 \%$, polipeptona $0.2 \%$, extracto de carne $0.1 \%$, extracto de levadura $0.1 \%$, sulfato de magnesio heptahidratado $0.5 \%$, solución salina ( $\mathrm{FeSO} .7 \mathrm{H}_{2} \mathrm{O} 0.1 \%, \mathrm{ZnSO}_{4}$. $7 \mathrm{H}_{2} \mathrm{O} 0.1 \%$, $\mathrm{MnCl}_{2} .4 \mathrm{H}_{2} \mathrm{O}^{2} 0.1 \%$ CuSO ${ }_{4} .5 \mathrm{H}_{2} \mathrm{O}$
$0.05 \%)$
$0.1 \%$ y agar $2.0 \%$, ph 7.0 (5). Los tubos se incubaron a $28^{\circ}$ C., 4-5 días, y luego se conservaron a 4\% $\mathrm{C}$. En el momento de usarse, la cepa fue repicada en placas a Agar Extracto de Malta 5 días a $28^{\circ} \mathrm{C}$. A partir de las mismas se preparó una suspensión acuosa usando Tween 80 como tensoactivo y se determinó la concentración de las unidades formadoras de colonias de tal supensión por recuento en Agar Extracto de Malta.

\section{Germinación de conidios de F.graminearum en medio sólido:}

Cincuenta nlde la suspensión de conidios del $\mathbf{F}$. graminearum NRRL $2830 \quad\left(10^{5}\right.$ macroconidios $/ \mathrm{ml}$.) fueron sembrados sobre placas de Agar Extracto de Malta e incubados a $28^{\circ} \mathrm{C}$. A distintos tiempos se determinó el porcentaje de macroconidios productores de tubos germinativos.

IV Germinación de conidios de F.graminearum en presencia de Streptomyces sp.:

La germinación de los conidios de F. gram!nearum se estudió en los siguientes casos:

a) Sembrando simultáneamente $0,5 \mathrm{ml}$. de la suspensión de Streptomyces sp. de $3.6 \times 10^{3}$ u.f.c. $/ \mathrm{ml}$. y $50 \mathrm{l}$. de la suspensión de macroconidios del Fusarium conteniendo $10^{5}$ coni- 
dios/ml. sobre Agar Extracto de Malta e incubando a $28^{\circ} \mathrm{C}$.

b) Sembrando $0,5 \mathrm{ml}$. de la suspensión del Streptomyces sp. de $3.6 \times 10^{3}$ u.f.c. $/ \mathrm{ml}$. en Agar Extracto de Malta incubando 24 horas a $28^{\circ} \mathrm{C}$ y posteriormente ${ }_{5}$ sembrado $0.5 \mathrm{ml}$ de la suspensión de $10^{5}$ conidios $/ \mathrm{ml}$. de Fusarium graminearum.

c) Enfrentando (sobre Agar Extracto de Malta) los macroconidos de Fusarium con $1 \mathrm{ml}$. del filtrado obtenido a partir del medio Extracto de levaduras glucosa inoculado con el Streptomyces sp. e incubando 5 días a $30^{\circ} \mathrm{C}$.

La germinación de conidios de $\mathbf{F}$. graminearum fue seguida de la misma forma que en las condiciones basales (punto III).

V Crecimiento. Determinación de la curva de crecimiento en medio sólido en condiciones basales:

Inoculos de $2 \mathrm{ml}$ de la suspensión de $F$. graminearum conteniendo $1.37 \times 10^{5}$ conidios $/ \mathrm{ml}$ fueron sembrados sobre placas de Agar Extracto de Malta y el crecimiento se estimó determinando el diámetro promedio (a diferentes tiempos) de las colonias obtenidas por incubación a $28^{\circ} \mathrm{C}$.

VI Crecimiento en presencia de Streptomyces sp.:

El crecimiento de F. graminearum fue estudiado:

a) Sembrando simultáneamente $2 \mathrm{ml}$ de la suspension de F.graminearum conteniendo $1.37 \times 10^{5}$ conidios/ml.y $0.5 \mathrm{ml}$ de la suspension de Streptomyces $3.6 \times 10^{3}$ u.f.c. $/ \mathrm{ml}$. sobre placas de Agar Extracto de Malta.

b) Sembrando $0,5 \mathrm{ml}$. de la suspensión de Streptomyces sp. de $3.6 \times 10^{3}$ u.f.c. en Agar Extracto de Malta incubando a $28^{\circ} \mathrm{C}$ durante 24 horas y luego sembrando $2 \mathrm{ml}$ de la suspensión de conidios de F. graminearum.

VII Determinación de la concentración de glucosa:

Se utilizo para la determinación de glucosa el método enzimático de la glucosa oxidasa (Wiener Lab.)'con un testigo de glucosa de $100 \mathrm{mg} / \mathrm{dl}$.

Se sembraron por separado $2 \mathrm{ml}$ de la suspepsión de F.graminearum NRRL 2830 de 1.37 x $10^{5}$ conidios $/ \mathrm{ml}$. y $0.5 \mathrm{ml}$. de una suspensión de Streptomyces sp. conteniendo $3.6 \times 10^{3}$ u.f.c. $/ \mathrm{ml}$., en medio de Extracto de Malta líquido conteniendo $1284 \mathrm{mg} / \mathrm{dl}$. de glucosa inicial. La glucosa residual fue determinada tomando alícuotas del medio inoculado a diferentes tiempos.

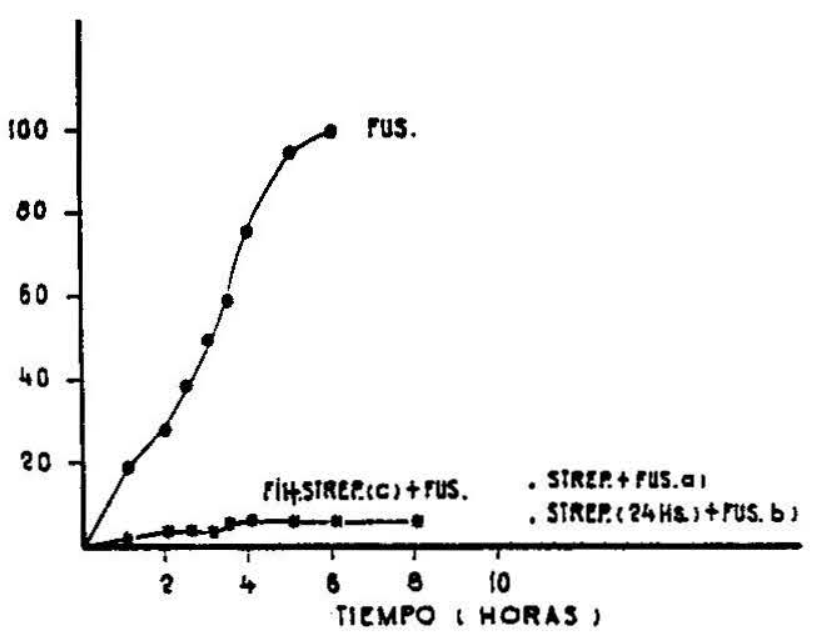

Gráfica \# 1

Curvas de germinación de los macroconidios del F. graminearum NRRL 2830 sembrados en AEM en condiciones basales, junto con un filtrado de Streptomyces sp. simultáneamente al Streptomyces sp. 024 horas después que el Streptomyces sp.

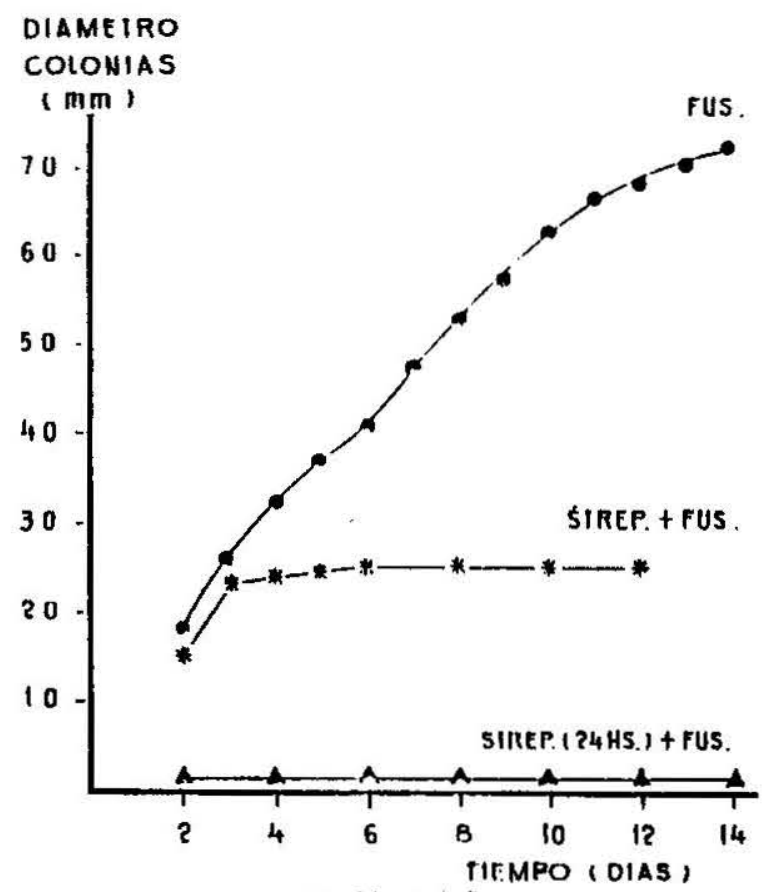

Grafica \# 2

Curvas de crecimiento del F. graminearum NRRL 2830 en AEM sembrado en condiciones basales, junto con Streptomyces sp. o 24 horas después que Streptomyces sp. 
Tabla \#1

Curvas de germinación de los macroconidios del F. graminearum NRRL 2830 sembrados en AEM en condiciones basales, junto con un filtrado de Streptomyces sp., simultáneamente Streptomyces sp. 024 horas después que Streptomyces sp.

\begin{tabular}{|c|c|c|c|c|}
\hline \multicolumn{5}{|c|}{ Porcentaje de conidios germinados } \\
\hline $\begin{array}{l}\text { Tiempo } \\
\text { (horas) }\end{array}$ & $\begin{array}{l}\text { Fusarium } \\
\text { solo }\end{array}$ & $\begin{array}{c}\text { Streptomyces } \\
+ \\
\text { Fusarium } \\
\text { (a) }\end{array}$ & $\begin{array}{c}\text { Streptomyces } \\
\text { (24 horas) } \\
+ \\
\text { Fusarium } \\
\text { (b) }\end{array}$ & $\begin{array}{c}\text { Filtrado } \\
\text { Streptomyces } \\
+ \\
\text { Fusarium } \\
\text { (c) }\end{array}$ \\
\hline $\begin{array}{l}1 \\
2 \\
2.30 \\
3 \\
3.30 \\
4 \\
5 \\
6\end{array}$ & $\begin{array}{l}20 \\
28 \\
39 \\
49.5 \\
59.5 \\
76 \\
95 \\
100\end{array}$ & $\begin{array}{l}0 \\
0 \\
0 \\
0 \\
0 \\
0 \\
0 \\
0\end{array}$ & $\begin{array}{l}0 \\
0 \\
0 \\
0 \\
0 \\
0 \\
0 \\
0\end{array}$ & $\begin{array}{l}2 \\
4 \\
4 \\
4 \\
6 \\
6 \\
6 \\
6\end{array}$ \\
\hline
\end{tabular}

Tabla \# 2

Curvas de crecimiento del F. graminearum NRRL 2830 en AEM sembrado en condiciones basales, junto con Streptomyces sp. 024 horas después que Streptomyces sp.

\begin{tabular}{|c|c|c|c|}
\hline \multicolumn{4}{|c|}{ Diámetro colonia (mm) } \\
\hline $\begin{array}{l}\text { Tiempo } \\
\text { (días) }\end{array}$ & $\begin{array}{c}\text { Fusarium } \\
\text { solo }\end{array}$ & $\begin{array}{c}\text { Streptomyces } \\
+ \\
\text { Fusarium }\end{array}$ & $\begin{array}{c}\text { Streptomyces } 24 \text { horas } \\
+ \\
\text { Fusarium }\end{array}$ \\
\hline $\begin{array}{c}1 \\
2 \\
3 \\
4 \\
5 \\
6 \\
7 \\
8 \\
8 \\
9 \\
10 \\
11 \\
12 \\
13 \\
14 \\
15\end{array}$ & $\begin{array}{l}- \\
13 \\
26 \\
35 \\
38 \\
41 \\
48 \\
53 \\
58 \\
63 \\
67 \\
69 \\
71 \\
73 \\
75\end{array}$ & $\begin{array}{c}-. \\
15 \\
23 \\
24 \\
24.5 \\
25 \\
25 \\
25 \\
25 \\
25 \\
25 \\
25 \\
-- \\
-- \\
-.\end{array}$ & $\begin{array}{l}0 \\
0 \\
0 \\
0 \\
0 \\
0 \\
0 \\
0 \\
0 \\
0 \\
0 \\
0 \\
0 \\
0 \\
0\end{array}$ \\
\hline
\end{tabular}




\section{Determinación del pH:}

Se tomaron alícuotas de los cultivos en distintos tiempos y se mitio el pH con un aparato Orion Research Digital Ionalyzer 501.

El pH del medio Extracto de Malta líquido utilizado fue de 6.65 .

Tanto las determinaciones de glucosa como las de $\mathrm{pH}$ fueron hechas por triplicado obteniéndose luego el promedio de ellas.

\section{RESULTADOS}

\section{1) Germinacion}

La determinaciones fueron efectuadas por triplicado y los valores medios se presentan en la Tabla \# 1 y en el Gráfico \# 1.

Tanto en el caso a) como en el b) no se observo la emisión de tubo germinativo hasta las 6 horas.

\section{2) Crecimiento.}

Los diámetros promedio de las colonias obtenidas por incubación a $28^{\circ} \mathrm{C}$ se muestran en el Gráfico \#2 y en la Tabla \#2. (Las determinaciones fueron realizadas por triplicado).

\section{3) Determinación de la concentración de glucosa:}

Las determinaciones fueron hechas por triplicado obteniéndose una disminución de la concentracion residual de glucosa en el medio empleado va $330 \mathrm{mg} / \mathrm{dl}$. para F.graminearum y a $940 \mathrm{mg} / \mathrm{dl}$. para Strptomyces sp. al cabo de 12 días.

\section{4) Determinaci6n de pH:}

Los promedios de las determinaciones indican que el pH del medio donde se cultivó F. gramilevearum disminuyo gradualmente hasta el día 7 (pH 5,45) para luego ascender hasta el dia 12 (pH 6,70).

Para el cultivo de Streptomyces sp. el pH descendio a 5.80 hasta los 12 días de incubación.

\section{DISCUSION}

Un principio básico de ecología comunitaria es que la supervivencia de una especie, tal como F.graminearum, depende de su habilidad para interactuar exitosamente con los factores abióticos y bioticos de su ambiente. Debido a que las prácticas de fumigación crean un ambiente que conduce a la proliferación del patogeno, un medio posible de control es establecer una comunidad que inhiba al patógeno en el suelo tratado.

La proliferación saprofítica de un patógeno puede ser controlada agregando antagonistas selectivos a suelos recientemente fumigados antes de que ocurra la reinvasión de este. De esta manera se puede aumentar la eficacia de las aplicaciones para el control biológico y se puede relizar frecuentemente el control de la enfermedad en el campo (8).

Cuando Streptomyces sp. creció conjuntamen. te con $\mathrm{F}$. graminearum fué determinante en alterar la germinación y el crecimiento de este hongo.

Los estudios de la germinación demostraron que la presencia del Streptomyces sp. disminurye el porcentaje de conidios germinados, siendo la inhibición total sólo en el caso en que este microorganismo fue sembrado con anticipación al F. graminearum.

Teniendo en cuenta que los Streptomyces son microorganismo típicamente conocidos por su producción de sustancias antimicrobianas y de crecimiento lento en medios sólidos, el efecto anterior podría atribuírse a la producción de metabolitos inhibidores que actuarían sobre la germinación de los conidios de F. graminearum más que a una competición por el sustrato.

Además sabiendo que la germinación de los conidios del F. graminerum es relativamente rápida (a las 6 horas el 100\% de los conidios emitieron tubos germinativos) es probable que la producción de estos metabolitos se retarde permitiendo en parte la emisión de tubos germinativos y por eso su efecto es sólo parcial.

Cuando se estudió la acción del filtrado de Streptomyces sobre la germinación, no se observó ningún efecto inhibidor significativo, lo que podría deberse a que el medio Extracto de levaduraglucosa no sea el apropiado para la síntesis de la sustancia inhibidora.

También se observó que al enfrentar Streptomyces sp. y F. graminearum, la inhibición del crecimiento del hongo fue completa únicamente cuando se sembró anticipadamente Streptomyces sp. tal vez por la acción de la sustancia inhibidora sobre la germinación. En el caso en que los dos microorganismos fueron sembrados simultáneamente, algunos conidios que no fueron afectadas puedieron germinar, continuando su desarrollo pero sin alcanzar las dimensiones observadas en ausencia de Streptomyces, obteniéndose colonias de crecimiento más restringido.

Fusarium graminearum metaboliza la glucosa con mayor velocidad que Streptomyces sp. por lo tanto se descartaria que el efecto inhibitorio sobre F. graminearum sea por competencia sobre ésta en el medio de cultivo.

Las variaciones del pH a lo largo de la experiencia para Streptomyces sp. son relativamente pequerias. F. graminearum acidifica el medio 
hasta 5.45 alrededor del día 7 , luego el pH camienza a elevarse hasta 6.70 el dia 12 . La influencia de Streptomycas sp. como modificador del $\mathrm{pH}$ del medio no es significativa por lo tanto no influiría en el efecto inhibitorio.
Aplicando estos conceptos, la utilización de microorganismos antagonistas presentes en el mismo suelo donde se hallan los hongos patogenos permitiría efectuar el control de pat6genos vegetales en el campo, disminuyendo la necesidad de agregar biocidas durante la labor agrícola.

\section{REFERENCIAS}

1) J.E. Smith and M.C.Moss, 1985. Mycotoxins, Formation, Analyais and Significance. John Wiley Sons Ed., Great Britain. Pág. 25-30.

2) Mirocha C.J. Watson S. \& Hayes W. Ocurrence of trichothecenos in samples from Southests Asia Associated with "Yellow Rain". Proc. V Interac. IUPAC Symp. on Mycotocins and Phycotoxins. Viena, 1-3 Sep. 1982. Pág. 130-133.

3) Moss M.O. J.M. Franck, 1985. Trichothecenes and Other Mycotodins. Bdited J.Lacey, Jonh Wiley y Sons. Ldd.

4) Broadbent P., K.F.Baker \& Y.Waterworth, 1971. Bacteria and actinomycetes antagonistic to fungal root pathogens in Australian soils. Aust. J.Biol.Sci. 24: 924944.
5) Ballesta J.P.G. and M. Alexander, 1972. Susceptibility of several basidiomycetes to microbial lysis. Trans. Br. Mycol. Soc. 58 : 481-487.

6) Etheridge D.E. 1972 Antagonistic interactions of wood inhabiting microorganisms and biological control of decay. In Biological control of forest diseases. Edited by V.A Nordin, pp. 37-52.

7) Rose S., Ching Yang $\mathrm{Li}$ and S.Hutchins, 1980. A streptomycete antagonist to Phellinus weiri, Fomes annosus and Phutophthora cinnamomi. Can-J.Microbiol. Vol 26: 583-587.

8) Marois J.J. and Mitchell D.S., 1981. Effects of Fungal Communities on the Pathogenic and Saprophytic Activities of Eusarium cxssporum f.sp. radicis-lycopersici. Phytopathology 71 (12): 1251-1256. 